\title{
Estação Barracão (Ribeirão Preto, SP): análise de preservação e usos do patrimônio industrial tombado.
}

Letícia dos Santos Borges ${ }^{1}$ Eduardo Romero de Oliveira ${ }^{2}$

Resumo: Esta proposta visa analisar as condições atuais de preservação e os modos de reutilização do patrimônio histórico tombado, particular para fins turísticos. Ao estudarmos a proposta de verificar seu uso atual, as formas de preservação ou difusão, tornou-se necessário conhecer e entender as políticas públicas de preservação, incluindo as estratégias de reutilização. Isto porque através delas se busca o planejamento das atuações e fases a serem seguidas ao longo de um processo de intervenção em áreas a serem preservadas. Espera-se que o projeto seja um facilitador da transmissão de informações sobre o valor histórico do patrimônio e também permita refletir se seu uso turístico contribui para difusão e preservação do mesmo.

Palavras chave: Patrimônio industrial; patrimônio ferroviário; memória; São Paulo; Estação Barracão.

Abstract: This present work seeks to analyze how is the current heritage status and industrial patrimony uses, particularly for tourism purposes. As we study the proposal of verify its actual using, the preservation methods or diffusion, became necessary to know and understand the public preservation policies, including the reuse strategies. That's why over them search to planning actions and phases to be followed during the long intervention process at the preserved areas. It's expected the project to be a facilitator way of the historical value and also allow the touristic uses contribute to dissemination and preservation in the same way.

Keywords: industrial patrimony; heritage railway; memory; Sao Paulo; Barracão Station.

Resumen: La presente propuesta tiene como objetivo analizar las condiciones actuales de conservación y reutilización del patrimonio histórico preservado, sobre todo con fines turísticos. Al estudiar la propuesta para verificar su uso actual, formas de preservar o de difusión, se hizo necesario conocer y comprender las políticas públicas de preservación, incluidas las estrategias de reutilización. Esto es porque a través de ellos buscan en la planificación de las actuaciones y las etapas a seguir a lo largo de un proceso de intervención en las areas a conservar. Se espera que el proyecto sea un facilitador de la comunicación de la información sobre el valor histórico de la equidad y también permiten reflejar su uso turístico contribuye a la difusión y preservación de la misma.

Palabras clave: patrimonio industrial; patrimonio del ferrocarril; memoria; Sao Paulo; Estación Barracão.

\section{Introdução}

O transporte ferroviário teve seu auge no Brasil no século XIX, passando a integrar alguns dos estados brasileiros, representado como principal meio de transporte de cargas e

${ }^{1}$ Graduanda UNESP Rosana - Curso de Turismo - lehborges_@hotmail.com

2 Professor Assistente Doutor UNESP - eduardo@rosana.unesp.br 
passageiros de maneira mais rápida, segura e em grandes quantias por longas distâncias. Ajudou a acelerar o processo de modernização do país, tendo grande importância para o crescimento e desenvolvimento de muitas regiões.

Foi motivo de grande relevância para se preservar hoje em dia os patrimônios históricos culturais materiais e imateriais, sendo instrumento que remete o passado, uma memória coletiva de grande valor dos diferentes grupos que formaram a identidade da sociedade brasileira. A preservação faz com que esses bens cheguem devidamente preservados às gerações futuras e também podendo ser objeto de estudo e fonte de conhecimento para aqueles que os visitam ou usufruam os mesmos.

A Companhia Mogiana de Estradas de Ferro foi fundada em 18 de março de $1872 \mathrm{com}$ quase 2.000 quilômetros de linhas, oferecendo seus serviços aos estados de São Paulo e Minas Gerais até 1971, quando foi incorporada à FEPASA - Ferrovia Paulista S/A. Neste período inúmeras retificações foram feitas, tornando o leito da linha atual diferente do original na maioria de sua extensão. No entanto, no final de 1997, os trens de passageiros deixaram de circular pela linha (CURY, 2004; GIESBRECHT, 2011).

A Estação Barracão que fez parte da linha - tronco da Companhia Mogiana, está situada no município de Ribeirão Preto - SP. Sua construção se deu no final do século XIX, devido à expansão do cultivo do café, tendo necessidade de um transporte mais rápido no local, e foi inaugurada somente em 1900, em primeiro de junho. Seu nome foi dado por causa da existência do "galpão" onde os imigrantes se dirigiam para serem cadastrados junto às fazendas cafeeiras e, com o passar do tempo, nomeou-se também os bairros ao seu redor, Barracão de cima (hoje Ipiranga) e Barracão de baixo (hoje Campos Elísios) (GIESBRECHT, 2011; INSTITUTO HISTÓRIA DO TREM, 2013).

Por volta de 1964, com a modificação da Linha - Tronco da Mogiana sendo transferida para fora da cidade, a estação passou a sair da nova estação de Ribeirão (Ribeirão Preto Nova), fazendo com que a linha antiga aos poucos ficasse sem uso (INSTITUTO HISTÓRIA DO TREM, 2013). Em 1982, no dia 07 de maio, o Barracão teve seu tombamento decretado pela CONDEPHAAT (Conselho de Defesa do Patrimônio Histórico, Arqueológico, Artístico e Turístico do Estado de São Paulo), visando preservar o valor histórico deste bem cultural e a memória coletiva dos grupos sociais, passando a ser Patrimônio histórico e arquitetônico do estado de São Paulo (CONDEPHAAT, 2011).

(C) Rev. Arqueologia Pública \begin{tabular}{l|l} 
Campinas, SP & v.9
\end{tabular} \begin{tabular}{|l|l|l} 
No.(11) & p.50-62 & suplemento
\end{tabular} ISSN 2237-8294 
Atualmente a Estação Barracão esta trancada, com peças e móveis antigos de trem, a espera de um museu ferroviário. O local foi abandonado e não recebe qualquer atenção visando à preservação que sua trajetória faz merecer. O elo que se tinha entre a população e a antiga ferrovia esta se perdendo com o tempo. As novas gerações já não conhecem a ferrovia e sua importância, sendo ignorada e esquecida a relação que se tem da ferrovia e suas origens.

A proposta da pesquisa é verificar seu uso atual, formas de preservação ou difusão e seu uso para fins turísticos. Neste sentido, entendemos que, ao estudarmos as formas de utilização, poderíamos avaliar se ela pode permitir a difusão do valor histórico do bem cultural ou mesmo ampliar este conhecimento.

\section{Objetivo}

O objetivo geral desta pesquisa foi analisar as condições atuais de preservação e a reutilização, particular para fins turísticos da Estação Barracão (bem tombado pelo CONDEPHAAT, proc. 21364/80). Em específico, buscamos informações sobre os processos estadual e municipal de tombamento do edifício, a fim de conhecer detalhes da valoração atribuída e os agentes locais envolvidos no processo; verificamos o estado atual de preservação e intervenções realizadas; identificamos os projetos de uso propostos para o bem; obtemos informações sobre as políticas de preservação estabelecidas na cidade (legislação de proteção, conselhos); e, por fim, buscamos informações sobre outro patrimônio industrial tombado (a Cervejaria Paulista), para o qual há projeto de uso cultural, para fins de comparação sobre a proposta de uso que Ihe foi estabelecida.

\section{Metodologia}

Para o levantamento de informações foi feito a verificação dos documentos de proteção legal da Estação Barracão. Estas informações foram buscadas junto aos órgãos de preservação estadual (CONDEPHAAT) e municipal (CONPPAC/RP), onde está depositado o processo de tombamento. Tentamos obter informações de caráter histórico, vistoria técnica no bem na época do tombamento e justificativas para o tombamento. Tinha-se o intuito de obter conhecimentos dos agentes locais, além de um contato prévio para conhecimento das ações realizadas após seu tombamento.

Posteriormente foram feitas entrevista com gestores públicos e funcionários de órgãos, como Secretaria do Turismo e da Cultura de Ribeirão Preto, a fim de verificar a existência de políticas de preservação estabelecidas através de legislação de proteção, criação ou 
funcionamento de conselhos de cultura e/ou patrimônio. Foi verificado ainda outros exemplos de proteção e reutilização aos bens tombados de caráter industrial na cidade.

Baseado na avaliação técnica presente no processo de tombamento, fomos ao local pesquisar sobre seu estado atual de preservação e as intervenções ocorridas em função de projetos de uso ou atividades realizadas no local. E em consonância com esta, outra linha de trabalho foi a avaliação da infraestrutura turística do local.

\section{Análise dos resultados}

\subsection{Processo estadual e municipal de tombamento}

Baseado no CREA (2008), o tombamento é o ato de reconhecimento de um bem de valor histórico, um instrumento legal de proteção, uma importante ação a ser tomada para garantir a preservação definitiva de um patrimônio. Seu processo é o conjunto de documentos do início ao fim das tramitações realizadas referente à solicitação de tombamento definitivo. Forma-se uma fundamentação teórica que justifica e comprova que o bem realmente possui o valor histórico. Deste modo, além de garantir a preservação do bem, resgata a memória coletiva e consequentemente a identidade cultural dos grupos sociais, impedindo destruições ou descaracterizações do mesmo, propondo sua reutilização para a comunidade (CREA, 2008).

Através da análise dos processos de tombamento da Estação Barracão, realizados pelo CONDEPHAAT e pelo CONPPAC/RP, foi destacado a importância do material histórico e permitiu melhor compreensão da valoração atribuída e os agentes locais envolvidos no processo. A solicitação do Tombamento da Estação Barracão ao CONDEPHAAT ocorreu por iniciativa do Lions Clube em 1979, com pretensões principais em conservar o patrimônio histórico, reutilizá-lo como Museu do Imigrante e administrá-lo. Já a solicitação feita pelo CONPPAC, ocorreu em 2009 pela Divisão de Preservação do Patrimônio Cultural da cidade, no entanto, basearam-se na cópia do processo de tombamento estadual. Por ser uma das primeiras estações ferroviárias da região, tinha-se essa grande relevância em preservá-la.

Durante o processo de tombamento estadual, a arquiteta Maria Regina Mattos apresenta diversas considerações sobre o bem, informações que permitem entender um pouco mais de sua construção arquitetônica, a importância histórica para a sua proteção e, por fim, destaca a proposta de conservação e reutilização que seriam dadas à antiga Estação Barracão após seu tombamento. Expõe que a proposta de desativação da Estação Barracão e criação do Museu do Imigrante, como forma de reutilização do espaço, é bastante coerente, 
pois haveria a revitalização interna e externa do bem que traria benefícios à população local. Pôde-se perceber também, ao folhear o processo, a ausência de um inventário dos objetos localizados dentro da estação, uma vez que faz parte do patrimônio ferroviário local.

Devemos ter consciência de que documentos como estes fazem parte do procedimento histórico ao dar valor histórico cultural a um bem. São de grande importância e devem ser mantidos para o melhor entendimento das gerações futuras ao aprofundar seus conhecimentos.

Vale lembrar que a palavra preservação, no Brasil, dispõe de uma variedade de tipos de ações, como registros, inventários, políticas públicas, educação patrimonial, e possuindo também as intervenções nos bens, como modos de reutilização, podendo assumir a forma de conservação ou restauração, considerando o restauro ser entendido como um ato cultural (KÜHL, 2008). A preocupação dada à preservação dos bens históricos no Brasil tornou-se uma ação efetiva quando se trata de evitar a demolição e a descaracterização do bem tombado, porém não é dada a certa manutenção que o bem realmente precisa, pois há casos, como exemplo a própria Estação Barracão, que, após ser tombado, foi abandonado e não recebe qualquer atenção visando a preservação que sua trajetória faz merecer.

Mesmo que o tombamento seja efetuado aos bens, se não houver políticas públicas de preservação, para proteger toda a área, o tombamento não será eficaz, pois não haverá fiscalização do mesmo, acarretando em deterioração natural ou até mesmo por pessoas sem consciência da importância que o bem traz a comunidade.

\subsection{Estado atual de preservação e intervenções realizadas}

Dias (2005) menciona que as intervenções planejadas visam proteger os bens históricos, propondo que um edifício de valor histórico possa ser reinserido na vida e nos diversos usos atuais pela sociedade. Baseado na proposta de verificar o estado atual de preservação e intervenções realizadas na Estação Barracão, constatamos que a única medida tomada como forma de preservação ao local, foi o tombamento estadual e municipal.

Entretanto, percebemos que a realidade atual em que se encontra o bem ferroviário é de abandono, porém não tão arruinado e descaracterizado em comparação a maioria dos bens industriais tombados na cidade. Mas é fato que a Estação não recebe os devidos cuidados que se faz merecer, por sua trajetória e seu tombamento. O prédio encontra-se trancado com grande parte do acervo guardado em seu interior e com invasores morando nas pequenas casas da vila ferroviária. Pode-se notar a presença de pichações em suas paredes, 
pequenos vestígios de mato alto e lixo entre os trilhos e demais espaços, portas, pinturas, madeiramento e tijolos, desgastados. Fatores de alteração e degradação que se deram com o passar do tempo, através do abandono, do descuido e invasão de pessoas no espaço.

Nenhuma atividade ou projeto de intervenção foram implementados na Estação. Assim, vemos que após sua desativação não houve ação alguma que contribuísse com sua conservação, assegurando a salvaguarda do bem. Vale ainda ressaltar que a conservação do patrimônio histórico em geral, exige medidas de segurança e um plano específico de manutenção para sua conservação constante. Assim, caso seja proposto intervenções na Estação Barracão, objetivando sua preservação, é essencial que se faça um estudo prévio de onde devam ser controladas e prefiguradas essas manutenções, a fim de respeitar a essência do bem histórico, evitando intervenções incisivas que possam comprometer a integridade histórica ou a autenticidade de sua construção (ICOMOS, 1964; TICCIH, 2003).

\subsection{Projetos de uso propostos}

A partir da incorporação do patrimônio industrial como novo bem cultural, colocou-se em prática vários programas de recuperação, restauração, valoração e reutilização do bem industrial, visando a salvaguarda e repasse do valor histórico atribuído. Neste sentido, a reinserção de uma edificação de valor histórico na vida cotidiana de uma cidade, pode gerar propostas de usos diversos, desde que sua reutilização seja compatível com as características arquitetônicas apresentadas pelo bem, de modo a preservar e não descaracterizá-lo (DIAS, 2005; KUHL, 2008).

Feito o levantamento de projetos de usos propostos para a Estação Barracão, obtivemos a proposta do Instituto História do Trem e do Instituto Paulista de Cidades Criativas e Identidades Culturais - IPCCIC, junto a Rede de Cooperação Identidades Culturais. Estas propostas tratam-se de reutilização da antiga Estação Barracão para fins turísticos, ambos tendo em vista a recuperação e preservação do patrimônio industrial, concedendo interação com a sociedade.

Neste sentido, podemos expor que o patrimônio industrial tem se mostrado um interessante recurso turístico, devido o consumo cultural ter se tornado uma prática muito comum dentro dos hábitos do tempo livre. Assim, a nova destinação de bens históricos para

I fins turísticos ganhou destaque promovendo projetos variados, com o objetivo da preservação, (ֶ) valoração e difusão do legado cultural (ABAD, 2008). Portanto, vale destacar que a Carta de Nizhny Tagil (2003) descreve que a nova forma de utilização, como modo de assegurar sua 
conservação, é aceitável, porém especifica que essa nova adaptação deve-se evocar a sua antiga atividade, mantendo a autenticidade de sua construção. A reutilização do patrimônio industrial, como uma oportunidade de reconversão e recuperação dos bens industriais obsoletos, pode ser atribuída a Estação Barracão, como forma de recuperação, preservação e reinserção a contemporaneidade.

Em específico, o Instituto História do Trem, entidade sem fins lucrativos, voltado à preservação do patrimônio ferroviário, realizou uma proposta de reutilização ao conjunto da Estação Barracão e de seu sítio, atribuindo-lhes um Museu Ferroviário junto com uma pequena linha férrea turístico pedagógica, onde propôs também reabrir a Praça Conselheiro Antônio Prado que fica no entorno da Estação. A proposta, segundo o Presidente do Instituto História do Trem, Denis Esteves, iniciar-se-ia pelo restauro do prédio da Estação, acrescentando maior parte da mobília e dos aparelhos originais, como na época do auge do período cafeeiro em Ribeirão Preto. As pesquisas de restauro, feitas previamente pelo Instituto, deram-se a partir de documentações originais da Companhia Mogiana e fotos da época. Assim, é de importância destacar que o restauro como ato crítico, embasado em análises formais e históricas, tendo o intuito de conservar, revelar os valores estéticos e históricos do monumento e repassar para as gerações futuras da melhor forma possível o bem industrial, deve se fundamentar respeitando o material original e os documentos autênticos (KUHL, 2008).

A restauração da Estação Barracão junto à reutilização apontados neste projeto, ajudará a reverter danos causados por fatores externos em função do abandono, pois mediante sua composição por materiais que se degradam com o passar do tempo, este reaproveitamento para uma nova função útil fará com que permaneça preservado por muito mais tempo (KUHL, 2008).

Por fim, o Instituto da História do Trem evidencia que a proposta de sediar o Museu Ferroviário na Estação Barracão é positiva, pois garante a preservação da história da cidade, além de apontar que, com as intervenções propostas ao bem e a reutilização da área pela sociedade, também agregaria valor no fomento da atividade turística na região. Este projeto idealizado pelo Instituto História do Trem já foi entregue à Prefeitura de Ribeirão em 2009 e até o momento estão esperando que seja transferida a Estação Barracão para o Município, pois pertence ao DNIT. Tal fato impossibilita devidas intervenções a serem realizadas ao bem.

(C) Rev. Arqueologia Pública \begin{tabular}{l|l} 
Campinas, SP & v.9
\end{tabular} No.(11) p.50-62 suplemento ISSN 2237-8294 
Já o segundo projeto de uso proposto à Estação Barracão, criado pelo IPCCIC junto a Rede de Cooperação Identidades Culturais, é a ideia de um Roteiro da Paisagem Cultural do Café. Essa proposta sugere quatro circuitos de visitação aos bens arquitetônicos, advindos da história do café de Ribeirão Preto, organizados por meio de sua distribuição geográfica. São apresentados 37 bens relevantes de valor histórico, arquitetônico e cultural, o qual a Estação Barracão faz parte do Circuito A (IPCCIC, 2013).

Segundo Adriana Silva, Presidente do IPCCIC, essa proposta engloba a ação da economia criativa, em que contribuirá para o resgate de identidades da história do café no município. O projeto aponta que estes bens arquitetônicos, se devidamente preservados e com propostas de ocupações alternativas de uso, roteiros como este criado, poderiam ser transformados em uma importante iniciativa da economia criativa, no qual auxiliaria na valorização da preservação do patrimônio cultural.

Até o momento esta proposta foi exposta em um livro e um documentário, elencando cada bem arquitetônico participante do Roteiro da Paisagem do Café, defendendo que os bens requerem atenção do poder público ou privado no modo de um programa de recuperação, dinamização, criativo e viável que estes bens merecem, como formas de preservação e repasse das variadas identidades culturais de Ribeirão Preto.

Ao ver as propostas acima visando a reutilização da Estação Barracão, vemos que, propostas de uso para fins turísticos, aliam-se como uma boa alternativa para evitar o abandono do bem, desde que gere impactos mínimos, aderindo a possibilidade de poder propiciar recursos financeiros para dar continuidade à realização do projeto aplicado ao bem (ABAD,2008).

\subsection{Políticas de preservação}

Os marcos legais que regem a preservação patrimonial são dispositivos que organizam as ações, estruturando procedimentos e ordenando o território, consideram os anseios e as necessidades da população (BRASIL, 2010). No caso de Ribeirão Preto, ao se tratar de políticas de preservação, vale ressaltar que, atualmente, a Lei №2.211 de 24 de agosto de 2007 institui junto a Secretaria da Cultura, o Conselho de Preservação do Patrimônio Cultural do Município de Ribeirão Preto - CONPPAC/RP, órgão colegiado de caráter consultivo e 1 deliberativo, encarregado de representar a comunidade e assessorar o Poder Público Municipal. Tem o objetivo de propor a proteção do patrimônio cultural municipal e sugerir a 
implantação de políticas públicas em assuntos referentes à preservação do patrimônio cultural do município de Ribeirão Preto.

Por essa lei tem atribuições e competências de definir as diretrizes para a política municipal de valorização e preservação do patrimônio cultural; coordenar e integrar as atividades públicas referentes a essa política; proceder a estudos para elaboração e aperfeiçoamento de recursos da política prevista; sugerir aos Poderes Públicos Municipal, Estadual e Federal medidas para cumprimento das exigências de execução dessa política; manter permanente contato com organismos públicos e privados, visando à obtenção de recursos, para valorização e preservação dos bens culturais do município; propor e colaborar na execução de programas educacionais e culturais que visem à preservação de patrimônio; acionar os órgãos competentes para localizar, inventariar, catalogar e documentar os bens culturais do município; deliberar o tombamento de bens móveis e imóveis de reconhecido valor à preservação da memória do município; adotar as medidas necessárias a que se produzam os efeitos do tombamento e outras ações de preservação; pleitear benefícios aos proprietários de bens tombados; apontar sanções previstas, a fim de garantir a preservação do patrimônio cultural do município.

Ainda caberá ao CONPPAC/RP por esta Lei a adoção de todas as medidas para a preservação dos bens culturais de valor histórico cultural; propor às autoridades competentes o tombamento dos bens culturais; sugerir a celebração de convênio com entidades públicas e particulares objetivando a preservação do patrimônio; promover a divulgação de estudos sobre a história do Município de Ribeirão Preto. Ressalta também que em nenhuma circunstância o bem tombado poderá ser destruído, demolido, mutilado ou modificado e só poderá ser reparado, pintado, restaurado ou de qualquer forma alterado, mediante autorização e acompanhamento do CONPPAC/RP.

\subsection{Cervejaria Paulista}

Ao fazer o levantamento de outro bem tombado de caráter industrial na cidade de Ribeirão Preto, em específico que estivesse sendo reutilizado para uso cultural, constatamos a Cervejaria Paulista. Buscamos informações sobre seu projeto de preservação e reutilização, a fim de ser feita comparações sobre a proposta de uso que the foi estabelecida, considerada para fins turísticos. Esta busca de informações se torna pertinente, pois o projeto de pesquisa não busca tratar apenas de um bem isolado e sim, também adquirir informações sobre outros 
bens, como outros exemplos de reutilização e políticas de preservação estabelecidas na cidade como um todo.

A antiga Companhia Cervejaria Paulista teve sua inauguração em 1914, tornou-se de grande importância para a história da cidade e hoje é denominada Patrimônio Histórico Cultural. Através da ida ao local, foi constatado o ótimo estado de conservação, aparentemente seguindo os moldes da original construção, no entanto, a mesma antes do restauro, encontrava-se em estado crítico de depredação. Seu prédio foi cedido em comodato pela Heineken do Brasil, controlado pela Kaiser, para a realização de um centro de produção audiovisual. Hoje, utilizado pelos Estúdios Kaiser de Cinema, tem como principal objetivo a contribuição para a consolidação de um Polo Cinematográfico e Audiovisual no interior de São Paulo.

Abad (2008) retrata que o patrimônio industrial como novo bem cultural, fez gerar programas de recuperação e valorização do bem de caráter industrial em diversos países, por serem importantes fontes de conhecimento e enriquecimento cultural. A maioria das reutilizações de bens tombados são voltados para a criação de museus, entretanto alguns edifícios acabam não seguindo o mesmo padrão. Como podemos observar, a antiga Cervejaria Paulista teve seu reuso de espaço voltado ao uso cultural, porém deu-se uma implantação diversificada e diferenciada das demais.

No processo completo de restauro da antiga Cervejaria Paulista, usaram-se plantas originais e trouxeram o prédio a sua versão original, dando o devido uso cultural. Para tomar todos os cuidados de preservação, o imóvel foi tombado pelo CONDEPHAAT em 2007 e pelo CONPPAC em 2008 e atualmente encontra-se em processo de tombamento pelo IPHAN. Já no caso da Estação Barracão seu tombamento pelo CONDEPHAAT ocorreu em 1982 e pelo CONPPAC em 2012, mas após a desativação total da Estação e de seus trilhos não houve nenhuma atividade ou intervenção implementada, estando fechada até o momento.

Ao ser feita a comparação dos bens (Estação Barracão e Cervejaria Paulista), podemos notar que se assemelham por serem patrimônios industriais, tombados pelos mesmos órgãos (o estadual e o municipal), por terem passado por momento de abandono e descaracterização, e por falta de políticas de preservação funcionais desde o início do tombamento. Os bens não eram pertencentes ao município, tendo que se solicitar o repasse para intervenções e reutilização. As propostas de reuso atribuídas tinham o intuito de garantir a preservação do edifício e seu entorno, dando-lhes uma função útil voltada ao turismo.

(C) Rev. Arqueologia Pública \begin{tabular}{l|l|} 
Campinas, SP & v.9
\end{tabular} No.(11) p.50-62 suplemento ISSN 2237-8294 
Há de se destacar que se deve respeitar a essência do bem, verificar se esta nova função é condizente, escolhendo um uso compatível com seus aspectos estruturais, a fim de dar apenas a manutenção necessária de preservação, assegurando a sobrevivência do bem, sem que descaracterize-o (KUHL, 2008). A reutilização por sua vez, se bem planejada, não sofrendo modificações rudes, contribui para a salvaguarda do contexto histórico do local, como forma de difusão da plenitude de sua autenticidade.

\section{Considerações finais}

Durante a realização da pesquisa, foi possível verificar limitações na proteção legal proposta à Estação Barracão, no qual seu tombamento se deu a nível estadual e municipal. Tal ação não foi suficiente para garantir a verdadeira preservação da mesma, estando atualmente abandonada e com fatores de degradação evidentes.

Vale ressaltar que mesmo que o tombamento seja efetuado a bens de valor histórico, se não houver políticas de preservação atuantes e funcionais, para proteger e proporcionar devidas manutenções, o tombamento não será eficaz, pois não haverá vistoria do mesmo, a fim de apontar problemas que afetem o bem. Deste modo, ocasionará deterioração natural em função do tempo ou deterioração por pessoas sem conhecimento do valor histórico que o bem representa para a comunidade em que está inserido.

Referente às políticas de preservação estabelecidas na cidade, dispõe-se da legislação de criação do Conselho de Preservação do Patrimônio Cultural - CONPPAC, órgão encarregado a assessorar o Poder Público Municipal em assuntos referentes à preservação do patrimônio cultural de Ribeirão Preto, onde tem atribuições e competências a serem cumpridas. No entanto, pouco funciona, pois certas atribuições não são exercidas igualmente a todos os bens, deixando alguns tornarem-se obsoletos, como é o caso da Estação Barracão que não recebe seus devidos cuidados.

Desde que a Estação foi desativada, não foi implantado nenhum uso ao bem e também não sofreu nenhuma intervenção visando sua conservação para que seja feito o repasse do valor histórico a gerações futuras. Neste sentido, durante a realização da pesquisa, constatamos a presença de dois projetos de uso propostos à Estação, por outros agentes sociais (um é o Museu da História do Trem e o outro a participação no Roteiro Cultura do Café), sendo a proposta de implantação do museu apresentado desde 2009, visando a recuperação e preservação do bem. Ambos os projetos são destinados ao uso turístico, porém 
estão estacionados e no momento nada se tem feito para dar continuidade e efetivação. Alega-se que, enquanto o bem ferroviário não for repassado ao município, nada pode ser feito.

Ao buscar informações sobre outro bem de caráter industrial tombado, a Cervejaria Paulista, no qual há projeto de uso cultural (o Estúdios Kaiser de Cinema), certificamos que a reutilização como forma de preservação, que envolvam o turismo, pode ser uma ótima alternativa para reverter o abandono causado ao patrimônio. Porém deve se levar em conta que estudos prévios devem ser feitos, provando a compatibilidade do novo uso, assegurando que as intervenções venham causar mínimos impactos, havendo incentivo de políticas públicas associadas a cidade.

A reutilização destes patrimônios se mostra como um grande benefício cultural, pois ajudaria em sua conservação, garantiria o repasse da memória da população local e daria continuidade aos bens associados ao passado, após ser reinserido na vida contemporânea, podendo adquirir variados usos atuais. Assim, podemos propor que o possível uso do patrimônio industrial, visando a Estação Barracão como exemplo de mais um bem industrial reutilizado na cidade, se faça uma proposta eficaz de preservação do mesmo. Por fim, como apresentado na pesquisa, é de suma importância não só a conservação dos bens históricos culturais, como também é de imprescindível relevância a reutilização destes, evitando assim o abandono, garantindo a conservação adequada destes patrimônios e permitindo a difusão do valor histórico do bem cultural, ampliando o conhecimento dos demais.

\section{Referências}

ABAD, Carlos J. Pardo. Turismo y patrimônio industrial. Madrid: Síntesis, 2008.

BRASIL. Ministério do Turismo. Turismo Cultural: orientações básicas. Ministério do Turismo, Secretaria Nacional de Políticas de Turismo, Departamento de Estruturação, Articulação e Ordenamento Turístico, Coordenação - Geral de Segmentação. - 3. ed.- Brasília, 2010.

CREA - SP- Conselho Regional de Engenharia, Arquitetura e Agronomia do Estado de São Paulo. Patrimônio histórico: Como e por que preservar - 3ª edição. São Paulo, 2008.

CURY, Paulo Rogério. História e imagens da Companhia Mogiana de Estradas de Ferro, 2004. Disponível em: <http://www.cmef.com.br>. Acesso em: 05 nov. 2014.

DIAS, Adriana Fabre. A reutilização do patrimônio edificado como mecanismo de proteção: uma proposta para os conjuntos tombados de Florianópolis. (Mestrado em Arquitetura). UFSC. Florianópolis, 2005. 
GIESBRECHT, Ralph Mennucci. Estações Ferroviárias do Brasil, 2011. Disponível em: <http://www.estacoesferroviarias.com.br/b/barracao.htm>. Acesso em: 15 nov. 2014. GOVERNO DO ESTADO DE SÃO PAULO. Secretaria da Cultura. Estação Barracão. São Paulo, $2011 . \quad$ Disponível em: <http://www.cultura.sp.gov.br/portal/site/SEC/menuitem.bb3205c597b9e36c3664eb10e2308ca 0/?vgnextoid=91 b6ffbae7ac1210VgnVCM1000002e03c80aRCRD\&ld=08bfd0db350af010VgnV CM1000004c03c80a__ _ Acesso em: 06 nov. 2014.

ICOMOS. Carta de Veneza. Veneza: 1964.

INSTITUTO HISTÓRIA DO TREM, Proposta de criação do museu ferroviário de Ribeirão Preto. Mensagem recebida por <dwesteves@yahoo.com.br> em 14 nov. de 2014.

KÜHL, Beatriz Mugayar. Preservação do Patrimônio Arquitetônico da Industrialização: Problemas Teóricos de Restauro. Cotia, SP: Ateliê Editorial, 2008.

RIBEIRÃO PRETO. Lei n².211 de 24 de agosto de 2007.

ROSA, Lilian Rodrigues de Oliveira; SILVA, Adriana (Org.). Paisagem Cultural do Café - Ribeirão Preto. São Paulo, 2013. IPCCIC - Instituto Paulista de Cidades Criativas e Identidades Culturais | Rede de Cooperação Identidades Culturais. $\mathrm{TICCIH}$, The International Committee for the Conservation of the Industrial Heritage. Carta de Nizhny Tagil sobre o património industrial. Julho 2003. Tradução da responsabilidade da APPI - Associação Portuguesa para o Património Industrial (Nizhny Tagil). 17 de Julho de 2003. Disponível em: http://ticcih.org/wp-content/uploads/2013/04/NTagilPortuguese.pdf>. Acesso em: 12 nov. 2014. 